\title{
On the Optimum Design of Air-Cored Tesla Transformers
}

\author{
E. Agheb, A. Hayati Soloot, K. Niayesh, E. Hashemi and J. Jadidian \\ School of Electrical and Computer Engineering, University of Tehran \\ P.O. Box 14395/515, IR-14395, Tehran, Iran
}

\begin{abstract}
In this paper, the effect of mutual inductance $(M)$ and its optimization on the output pulse rise time in Tesla coils is investigated. A numerical method is proposed to calculate the mutual inductance in a Tesla coil. The method is verified by performing some experiments. Eventually, the conditions for maximum voltage gain for ordinary Tesla coil and autotransformer connected one are surveyed.
\end{abstract}

PACS numbers: $52.90 .+\mathrm{z}$

\section{Introduction}

Tesla coil is an electrical device capable of developing high potentials ranging from a few hundreds of kilovolts up to several megavolts; the voltage is produced as AC, with a typical frequency of 50-400 kHz. Tesla coils, which are typically operated in pulsed mode, have strong coupling with pulse widths varying from some nanoseconds up to several hundreds of microseconds according to the particular application. Due to their capabilities, Tesla Transformers have found various applications such as in high voltage Subnanosecond Pulsers [1], aging of insulators and high frequency solid insulation testing [2]. The prominent effect of coupling on the performance of Tesla coils necessitates the investigation of mutual inductance $(M)$ calculation methods. Analytical methods have been applied to calculate $M$ for Tesla coils with rectangular cross-section conductors [3, 4]. The closed-form expressions of these methods result in complete elliptic integral of first and second kind and Neumann's Lambda function, which makes the expression to seem complicated for users. The method proposed in this paper is a combined analytical and numerical method based on magnetic vector potential $(\boldsymbol{A})$ and Neumann's method which can be easily comprehended and convenient to be used [5]. Besides, the configuration role in optimizing $M$ and voltage gain are investigated.

\section{Theoretical approaches for mutual inductance optimization}

In general, any Tesla coil can be considered as a combination of two circular coaxial windings. The total mutual inductance $\left(M_{\text {total }}\right)$ of such a combination is sum of all $M_{i j}$, which is the mutual inductance between $i$-th turn of primary winding and $j$-th turn of secondary winding and $n_{1}$ the number of primary windings and $n_{2}$ the number of secondary windings. In this way, the calculation of the mutual inductance of any arbitrary Tesla coil can be reduced to find a general formulation for $M_{i j}$. To formulate $M_{i j}$, the produced magnetic vector potential ( ) on $j$-th turn of secondary winding should be calculated with consideration of a distributed current source on $i$-th turn of primary winding (see Fig. 1).

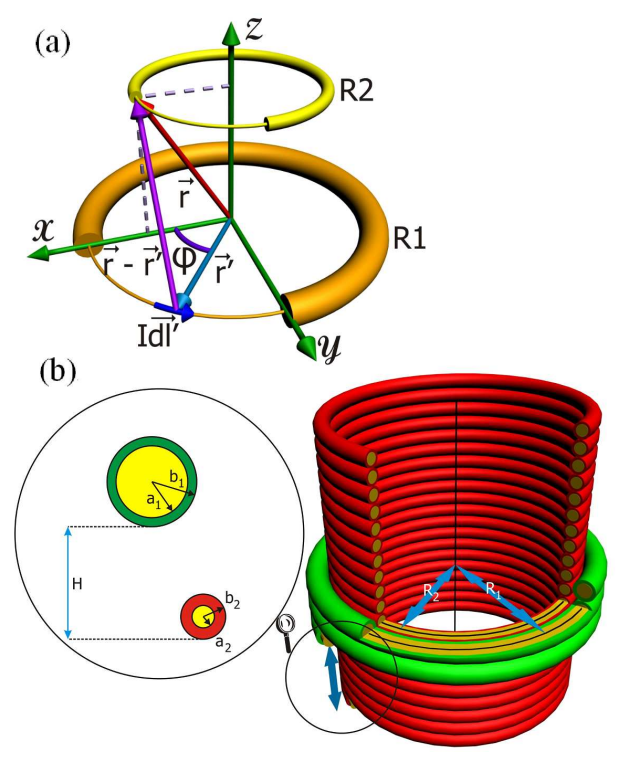

Fig. 1. (a) Two rings of inner and outer winding in a Tesla coil, (b) Tesla coil configuration.

Applying the Neumann method and calculating the magnetic flux through $j$-th turn of secondary winding, the following expression can be derived [5]:

$$
\begin{aligned}
& M_{i j}=\frac{\psi_{i j}}{I_{i}}=\frac{\mu_{0} R_{1} R_{2}}{2} \\
& \times \int_{0}^{2 \pi} \frac{\cos (\varphi) \mathrm{d} \varphi^{\prime}}{\sqrt{z_{i j}^{2}+R_{1}^{2}+R_{2}^{2}-2 R_{1} R_{2} \cos (\varphi)}} .
\end{aligned}
$$




\section{Experimental and simulation results for $M$ calculation}

\subsection{The relation between $M$ and $H$ and experimental validation}

The height of outer winding (LV) alters $M$ (See Fig. 2a). Thus, the optimum $M$ can be achieved while the outer winding is in the middle. According to simulations, the curve in line format, having outer winding in the middle, Tesla coil provides an increase of $38 \%$ in $M$ in this case. The dots in Fig. 2a represent the experimental measurements for mutual inductance of Tesla coil with mentioned characteristics.

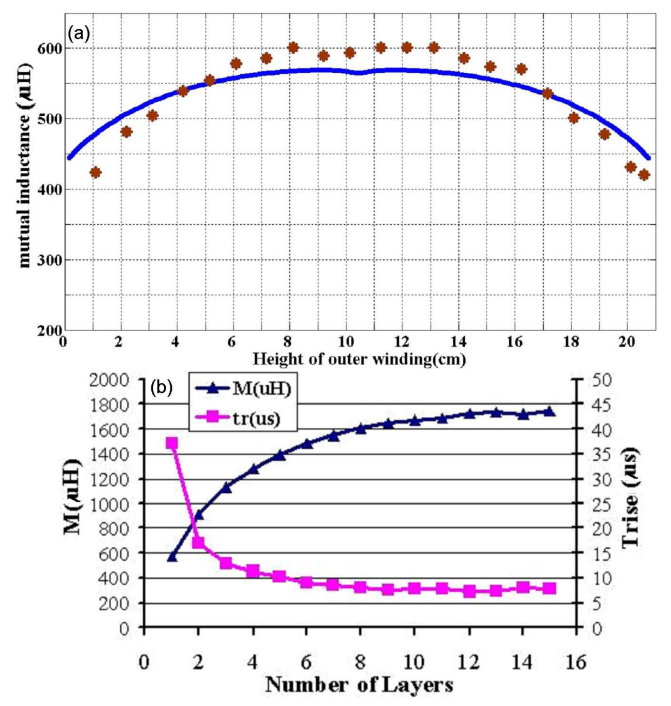

Fig. 2. (a) Mutual inductance of a Tesla coil with $8 \mathrm{~cm}$ radius. Primary winding $n_{1}=8, a_{1}=0.56 \mathrm{~mm}$, $b_{1}=1.56 \mathrm{~mm}$, secondary winding $n_{2}=767, a_{2}=b_{2}=$ $0.15 \mathrm{~mm}$, (b) mutual inductance of mentioned Tesla coil in (a) while splitting it to layers (curve with triangles).

\subsection{The relation between $M$ and rise time with number of layers}

The more layers the high voltage winding has, the more $M$ is achievable for Tesla coil. But, there is an optimum for $M$ while increasing the number of layers with fixed wire length. It approximately occurs when the height of each layer of $\mathrm{HV}$ winding is equal to the height of low voltage winding. Considering the dimensions of mentioned Tesla coil in Fig. 2a, we simulated it as multi-layer Tesla coil while the wire length of $\mathrm{HV}$ winding is constant (curve with triangles in Fig. 2b). The position of the LV winding is selected in the middle. In this configuration, when there are 15 layers, the height of multilayer $\mathrm{HV}$ winding is equal to the height of the LV winding (outer winding). Therefore, $1800 \mu \mathrm{H}$ is the possible optimum for this configuration. The rise time of output voltage sharply decrease to half when $M$ increases due to splitting $\mathrm{HV}$ winding to two layers (curve with squares in Fig. 2b). Splitting HV winding to more layers causes a slight increase in $M$ and small reduction in rise time simultaneously. The mesh of mutual inductance is depicted in Fig. 3 while the HV winding is split to various layers. In this figure $M$ between LV winding and different layers of $\mathrm{HV}$ winding is shown and the slight increase in $M$ from inner layer to outer one can be derived.

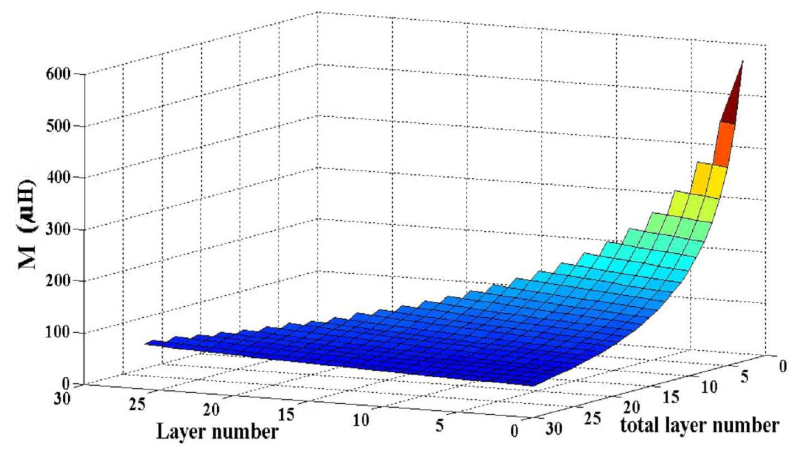

Fig. 3. Mutual inductance between LV winding and different layers of $\mathrm{HV}$ winding for mentioned Tesla coil in Fig. 2a. The total number of HV layers varies between 0 and 30 .

\section{Gain optimization of Tesla coil}

Discharging a charged capacitor with voltage $V_{1}$ in the primary side of a Tesla coil and solving the related differential equations, the maximum gain for a Tesla coil can be found as $[6]$ :

$$
\begin{aligned}
G & =\left.\frac{v_{2}(t)}{V_{1}}\right|_{\max }=\frac{2 k}{\sqrt{(1-T)^{2}+4 k^{2} T}} \sqrt{\frac{L_{2}}{L_{1}}}, \\
k & =\frac{M}{\sqrt{L_{1} L_{2}}}, \\
T & =\frac{\omega_{1}^{2}}{\omega_{2}^{2}}=\frac{L_{2} C_{2}}{L_{1} C_{1}} .
\end{aligned}
$$

When the application is for a noninverting transformer and primary to secondary isolation is not required, it is advantageous to use an autotransformer connection [7]. The better performance of autotransformer connected Tesla coil is explicit when the ratio $N$, which is $n_{2} / n_{1}$, is not so high because this better performance is due to the change in ratio from $N$ to $N+1$ which results in stronger coupling. Considering the mentioned condition in [6] for a Tesla coil with autotransformer connection, Eq. (5) for the maximum gain in this connection will be derived 


$$
G_{\mathrm{AT}}=\left.\frac{v_{2}(t)}{V_{1}}\right|_{\max }=\frac{2\left(k \sqrt{L_{1} L_{2}}+L_{1}\right) C_{1}}{\sqrt{\left(L_{1} C_{1}+C_{2}\left[L_{1}+L_{2}+2 k \sqrt{L_{1} L_{2}}\right)\right]^{2}-4 L_{1} L_{2} C_{1} C_{2}\left(1-k^{2}\right)}} .
$$

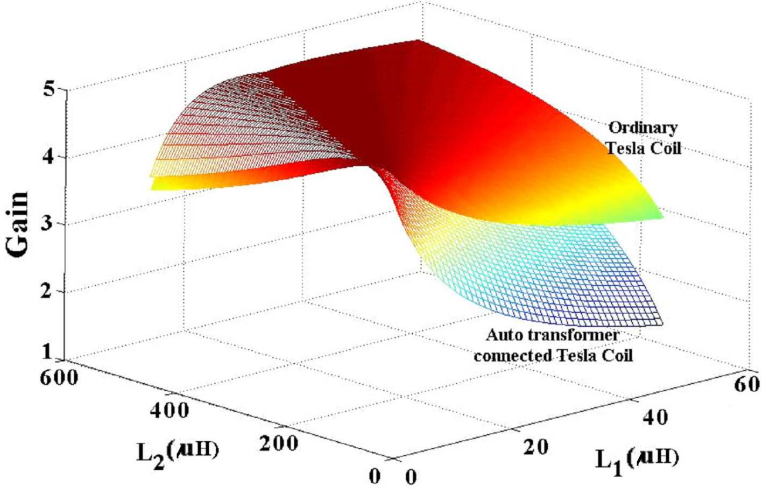

Fig. 4. Gain of an ordinary Tesla coil in comparison with autotransformer connected Tesla coil $(k=0.9$, $\left.C_{1}=50 \mathrm{nF}, C_{2}=2 \mathrm{nF}\right)$.

Comparing Eqs (2) and (5) for values of $N$ less than 10, we find that the maximum gain can get higher amounts in autotransformer windings for higher $L_{2} / L_{1}$. By the way, the sensitivity of gain to $L_{2} / L_{1}$ ratio changes is greater in autotransformer windings (see Fig. 4).

\section{Conclusions}

Based upon above analysis, the Tesla coil configurations which optimize the mutual inductance is splitting the $\mathrm{HV}$ winding to several layers while the wire length is constant. Autotransformer connected Tesla coil improves the coupling and Tesla coil performance.

\section{References}

[1] S. Brussaard, D. Vyuga, IEEE Trans. Plasma Sci. 32, 1993 (2004).

[2] C. Boonseng, P. Apiratikul, IEEE Conf. Elec. Ins. 248 (2002).

[3] D. Yu, K.S. Han, IEEE Trans. Magn. 23, 3916 (1987).

[4] S.I. Babic, C. Akyel, IEEE Trans. Magn. 42, 1661 (2006).

[5] K. Niayesh, H. Ghorbani, A. Hayati-Soloot, in: 51st Internationales Wissenschaftliches Kolloquium, Technische Universität Ilmenau, 2006, p. 479.

[6] M. Denicolai, Helsinki University of Technology, PhD Thesis 2001, p. 50.

[7] J.P. O'Loughlin, J.D. Sidler, G.J. Rohwein, IEEE Power Modulator Symp., 1988, p. 325. 